\title{
José Luis Gómez Mompart, Juan Francisco Gutiérrez Lozano, Dolors Palau Sampio (editores). La calidad periodística: teorías, investigaciones y sugerencias profesionales.
}

Bellaterra: Universitat Autònoma de Barcelona; Castelló de la Plana:

Universitat Jaume I; Barcelona: Universitat Pompeu Fabra; València:

Universitat de València, 2013. 203 páginas (Aldea global; 26).

Es un permanente desafío para la vida democrática, para la formación de la opinión pública y para la sustentabilidad de los medios periodísticos lograr y mantener la calidad. Este concepto ha adquirido diferentes alcances y valores, y su ponderación comprende una diversidad de herramientas cuantitativas y cualitativas, relacionadas con el medio, el contenido, las competencias profesionales, el pluralismo por nombrar algunos aspectos. Su alcance parece depender más bien de acciones ejecutadas aún de modo intuitivo en parte, no del todo sistematizadas.

La calidad periodística busca encontrar principios de esa sistematización. Expone una variedad de estudios en busca de dar con los indicadores más fiables para determinar la calidad de un contenido periodístico, que van desde la propiedad de los medios, la organización de los equipos, las redacciones, los diversos agentes implicados, pasando por el tratamiento de fuentes, la edición y las relaciones con las audiencias. Considerada como proceso y como producto, la calidad es un bien intangible, estimable por los actores del proceso y por los usuarios del producto, que prestigia a un medio, cimenta su credibilidad y coopera en su sustentabilidad.

Los estudios publicados se aplican a diarios gratuitos y de pago, gestión de fuentes informativas, agencias de noticias, medios digitales, trabajo en red, participación de las audiencias, informativos de televisión, televisión digital terrestre, medio ambiente. Recorren medios, prácticas, temas, actores; enuncian definiciones de calidad periodística, discuten sobre sus alcances, exponen métodos de trabajo.

Después de la introducción de Josep Lluís Gómez Mompart y el capítulo de planteo general -también de Gómez Mompart con Dolors Paulau Sampio (dos de los tres editores del volumen)-, abre los estudios particulares el trabajo dedicado al valor agregado periodístico (VAP), un instrumento desarrollado en conjunto por la Pontificia Universidad Católica de Chile y la Pontificia Universidad Católica Argentina. El capítulo de María del Mar García Gordillo, Ofa Bezunartea Valencia e Inés Rodríguez Cruz expone cómo el VAP se ha aplicado a distintos medios (prensa, radio, televisión) en diferentes países (Chile, la Argentina, Colombia, Perú, 
Ecuador, España) con enfoques amplios o restringidos temáticamente (por ejemplo, en información política, ambiental, aeronáutica o bélica).

El VAP parte del producto y permite arribar al proceso que le dio origen: desde lo que el medio es capaz de hacer hasta lo que efectivamente realiza, calificando el trabajo profesional del periodista. Segmenta el estudio en dos etapas: la selección de la noticia y su creación. Así, surgen dos conjuntos de variables para cada período, que consideran el nivel de selectividad de la noticia, el nivel de acceso (fuentes), la equidad o equilibrio, para la primera, y el estilo, el contenido y el énfasis, para la segunda. El capítulo expone también los estándares del CIP (calidad de información periodística), que abarcan aspectos como confiabilidad, relevancia, interés, proporción, precisión y calidad, entre otros.

Roberto de Miguel Pascual y Rosa Berganza Conde analizan periódicos de pago y gratuitos en España. Problematizan los abordajes sobre la calidad basados en aspectos de contenido, en las expectativas del lectorado y en la tabloidización o cambio de formato como un factor decisivo para medir calidad. La hipótesis que guía el estudio se basa en que los tabloides gratuitos han lesionado la calidad de la prensa española, de modo que el estudio se aboca tanto a los aspectos morfológicos cuanto a los de contenido.

Los resultados del estudio son paradójicos en algunos indicadores, puesto que examinados ambos aspectos en una muestra de 7000 piezas de medios de pago y gratuitos, en la prensa considerada de referencia y en los diarios de distribución gratuita no se encuentran diferencias de peso en el trabajo de fuentes identificadas, un aspecto decisivo para la estimación. Con respecto de la búsqueda de interactividad, por ejemplo, es la prensa gratuita la que supera a la de pago con mayor aproximación al lector.

El capítulo siguiente, de Andreu Casero Ripollés y Pablo López Rabadán, asume el estudio del trabajo con fuentes informativas en el periodismo español, elemento crítico para la consideración de la calidad. Los autores exponen indicadores de calidad internos (relacionados con el proceso de producción) y externos (relativos a los efectos sociales de la información). Los internos se orientan a la agenda de contactos del periodista, que define su estatus, la verificación o contraste de fuentes, la transparencia en la atribución, la relevancia (cantidad, variedad y prestigio de fuentes) y la reducción de la incertidumbre. Los indicadores externos son la credibilidad, que potencia o mengua la calidad de la noticia; la influencia del periodista y la información, que incrementa la posición de referencia e incide en el resultado económico; el pluralismo social y la diversidad (reduciendo el peso de fuentes oficiales y gubernamentales), $y$ la participación de usuarios, sobre todo a partir de las redes sociales.

La propuesta del estudio pone énfasis en el trabajo de fuentes como un elemento crítico en la medición de la calidad periodística y advierte sobre un crecimiento o sobrerrepresentación de las fuentes 
institucionales en demérito de la de los ciudadanos y la sociedad civil. Aun con el incremento de la presencia gracias a la web 2.0, todavía priman las fuentes oficiales, lo que impide desarrollar un periodismo multiperspectivista.

Enric Marín Otto, Pablo Santcovsky Reschini y Adrían Crespo Ortiz abordan la calidad de las agencias de noticias en un momento peculiar de su historia, con la circulación de la información por redes electrónicas, una "desterritorialización de los espacios comunicativos" (p. 93) y con cambios en la dimensión temporal, entre otros factores. La saturación informativa, su disponibilidad abierta, en flujo y permanente, ha supuesto un perjuicio para la calidad y la credibilidad periodísticas, y las agencias lo experimentan de modo acusado con su invisibilidad en las menciones de las piezas periodísticas o con el uso de la expresión genérica "agencias" que resuelve pobremente el uso de informaciones de diversas agencias fuente. Los autores proponen el uso de firmas personales para las noticias de agencia en vez del anonimato, lo que permitiría incrementar la calidad del contenido entregado y mejoraría la visibilidad de la agencia misma.

Mónica Parreño Rabadán estudia los argumentos que los periodistas sostienen en relación con la calidad. El estudio, de metodología cualitativa (con entrevistas en profundidad), aborda el campo periodístico (según Pierre Bourdieu) tensionado por las audiencias, la mercantilización de las noticias y sus propias expectativas. Tratar el campo periodístico con los argumentos de sus propios actores permite conocer la visión de la calidad (en mengua en las últimas décadas) y la explicación de sus causas y razones. Las principales explicaciones del descenso en la calidad son - para los periodistas - la crisis económica y la adaptación a las nuevas tecnologías.

En el capítulo dedicado al trabajo periodístico en red, Concepción Pérez Curiel, Inés Méndez Majuelos y José Luis Rojas Torrijos estudian la participación de las audiencias en el llamado periodismo ciudadano y la mediación profesional. Así distinguen entre fórmulas participativas directas e indirectas, con blogs, wikis, cuentas de redes sociales, comentarios en foros o videos y otros archivos que se suben a internet desde las plataformas de los medios. Esta participación ciudadana genera un rico debate sobre la pertinencia del trabajo periodístico y sobre otros formatos que conviven con los periodísticos pero no se confunden con ellos, a los que los autores llaman "formatos comunicativos". Los aportes de carácter amateur carecen de procedimientos tales como la verificación, el contraste y la contextualización propias del periodismo. Así considerado, el aporte de ciudadanos a la oferta informativa no compite con el trabajo bien hecho de los periodistas. Es una oportunidad para investigar las rutinas profesionales y producir mejoras, sobre todo en las competencias, para que se incremente la calidad percibida y las audiencias prefieran esos productos, resultado de un trabajo al que se le han aplicado los debidos controles. 
Del mismo modo, el siguiente capítulo de Carlos Ruiz, Pere Masip, David Domingo, Javier Díaz Noci y Josep Lluís Micó continúa examinando el papel de las audiencias en el periodismo $2.0 \mathrm{y}$ exponen las formas conversacionales de los ciberdiarios con sus públicos, especialmente por vía de comentarios: la necesidad de registrarse para debatir, el alcance de la moderación con el uso de algoritmos y la posibilidad de que los usuarios cuestionen o muestren su disconformidad. En el límite, al lector devenido en periodista, por ser fuente en un lugar privilegiado o por hacer oír su voz con un medio como un blog, le caben las mismas exigencias de credibilidad de un periodista.

En los cibermedios, además, la información que el mismo usuario provee sobre lecturas y consumos haciendo clic, entraña el riesgo de convertirlo en un gatekeeper que decide sobre lo que ha de ofrecerse. La "soberanía comercial" (p. 144) de dar solo lo que le interesa al lector se impondría así al servicio público que constituye un medio y podría distraer de su objetivo primero en una democracia.

Sobre la calidad en televisión, Estrella Israel Garzón y Ricardo Ángel Pomares Pastor estudian informativos de televisión española, atendiendo a aspectos tales como las tensiones entre servicio público y negocio privado o entre espectáculo e información; la variedad de fuentes, contenidos, géneros; el papel de estándares y modelos suministrados por las mismas cadenas o por otras agencias, como universidades $\mathrm{u}$ organismos mundiales, y los procesos de significación del discurso audiovisual, especialmente en lo referido a estereotipos y a formas de banalización de comunidades.

También orientado a televisión, María Luisa Humanes y María Dolores Montero dedican su capítulo a la TDT (televisión digital terrestre) en relación con el pluralismo interno, entendido como "la presencia de diversidad de valores, intereses y actores políticos y sociales" (p. 164) y diferenciado del pluralismo externo o presencia de organizaciones con diferentes puntos de vista. La concentración de la propiedad no ha desarrollado el pluralismo externo y ha causado una mercantilización en los contenidos y un debilitamiento de la televisión pública. De este modo, el pluralismo interno se constituye en un factor decisivo para mantener la calidad de la información televisiva. Las autoras proponen un protocolo de análisis de la calidad de ese pluralismo, que se basa en tres dimensiones: política, social y cultural, con indicadores clásicos (temas, actores, fuentes, ámbitos geográficos), temáticos, estilísticos, de duración, estructurales, entre otros. El análisis del sistema, las recomendaciones de consejos audiovisuales y la percepción de los públicos debiera incrementar la calidad de los contenidos periodísticos de la TDT para aumentar, a su vez, el debate público.

Cierra el volumen un estudio aplicado a la calidad de la información sobre el medio ambiente, de Inés Rodríguez Ruiz. La posibilidad de estudiar calidad y temáticas propone un campo fecundo para la investigación académica. La información ambiental es necesaria y valiosa en las agendas, por 
su importancia en sí y por las proyecciones económicas y políticas. Así entendida, la investigación dedicada a diarios españoles busca conocer cuánto se publica y cómo, sobre qué temas específicos, de qué procedencia (ámbito geográfico y fuentes) y con qué profundidad. Una de las principales conclusiones del estudio, además de las que podría compartirse con cualquier otro del volumen (extensión, tratamiento, agenda), exige la necesaria cooperación entre los medios y las comunidades científicas.

El libro se cierra con una bibliografía básica sobre el tema, que no se superpone completamente con la de los estudios particulares y ofrece otros caminos a los estudiosos e investigadores.

Entendido en su diversidad, el concepto de calidad abre un abanico de posibilidades para el abordaje y eso mismo entraña sus desafíos: ¿es la calidad un valor con criterios estables, universales, orientadores para la producción periodística y para la estimación de un producto? ¿Cómo considerar la calidad del producto de un medio que llega a vastas audiencias pero que ofrece un contenido sin valor agregado? ¿Cómo estimarla en los contenidos propios pero escasamente variados, que no ofrecen a la audiencia panoramas integrales, globales? ¿Cómo intervienen los medios digitales en reconfigurar los indicadores que miden calidad? ¿Todos los aspectos evaluables merecen igual ponderación? ¿Cómo, finalmente, se puede trabajar en la planificación a partir de su evaluación para mejorar la calidad?

\section{Marita Grillo}

Universidad Austral. Facultad de Comunicación mgrillo@austral.edu.ar 